\title{
Analysis of Accounting Problems of Carbon Emission under Low Carbon Economy
}

\author{
Weiguo Lu \\ The Engineering \& Technical College of Chengdu University of Technology, Leshan, Sichuan, \\ 614000
}

Keywords: Low Carbon Economy, Carbon Emission, Accounting Problems

\begin{abstract}
Carbon emissions accounting is a reflection of low-carbon economy. Although carbon emissions trading is the most effective means of reducing greenhouse gas emissions under the market economy, the absence of authoritative guidelines at home and abroad leads to significant autonomy in the accounting treatment of carbon emissions in practice And arbitrariness, which has a significant negative impact on the comparability of financial information and the decision-making of information users. Therefore, it reflects these effects in the financial statements in a timely and accurate manner and how to develop unified accounting standards to regulate the accounting treatment of carbon emissions trading to minimize these negative effects is a hot and difficult problem in accounting theory. In this context, it is very meaningful to systematically analyze and discuss the accounting issues related to carbon emissions trading.
\end{abstract}

\section{Introduction}

When the carbon emission right becomes a commodity for sale, it is necessary to make accurate accounting confirmation, measurement and disclosure of the value of the commodity through a applicable unified method. Although the carbon emission rights trading as the most efficient means of pollution control under the market economy system has been widely used in the world, but at this stage of Chinese carbon emissions trading accounting system for the less systematic research has not yet been developed The Moreover, China has no compulsory emission reduction obligations at this stage, there is no relevant domestic laws on carbon emissions to make the relevant provisions of carbon emissions in China does not constitute a real right, Chinese carbon emissions trading and international Of the carbon emissions trading is essentially different, we must recognize this point to explore the specific situation of Chinese carbon emissions trading accounting model. And domestic scholars in the discussion of carbon emissions of the accounting problem is to focus on carbon emissions in the accounting confirmation and measurement issues, there is no carbon emissions of the report and disclosure of a systematic analysis and discussion, so that carbon emissions The logical structure of the accounting system is not perfect. It is of great theoretical significance to systematically discuss the accounting problems of carbon emission rights in China before the formulation of carbon accounting standards at home and abroad.

\section{Carbon Emissions Trading Theory}

Due to the existence of externalities, relying solely on the market mechanism is unable to achieve optimal allocation of resources. There are two ways to solve this problem, one way is to use administrative management to limit the scale of externalities, for example, the provisions of the sewage standards, the provisions of governance techniques, limit the discharge sites, limit the sewage time, etc .; another method Is to use incentives to try to make the main pollutants to bear their external costs, that is, efforts to achieve the externalization of internalization, the practice of taking the main method is the collection of carbon taxes and sewage taxes. For a long time, carbon dioxide-dominated greenhouse gas (GHG) emissions have been seen as a public resource. As mentioned above, an effective way to solve the problem of carbon emissions externality is to solve the problem of property rights in the carbon emission space and to internalize the externalities. Carbon emissions trading is essentially to define the emission rights of carbon dioxide, the carbon 
emissions of space market, commercialization, quantitative, making it a production or consumption process must pay a certain price to get the rare resources to be from the root Eliminate externality. The economic reason for the delivery of carbon emissions is the scarcity of resources, since it is only possible to become exchangeable when a resource is scarce. A long time ago, when the productivity is low, the economy is underdeveloped, environmental resources are still quite rich, air, environment and other resources are regarded as inexhaustible public goods, not scarcity. With the progress of society and the improvement of the level of productivity, the demand for environmental protection is increasing, and the purification function of environmental resources is difficult to meet the needs of human production, life and consumption at the same time. Thus, contradictions, conflicts and competition have arisen the multiplicity of environmental functions and the scarcity of resource values is increasingly prominent. It is precisely because of this scarcity increasingly attract people's attention, and even developed into a short period of time in the rapid appreciation of the goods. Carbon emission rights are a kind of environmental property rights. The state or local government allocates this scarce resource to enterprises or the public through free distribution or paid purchase, and establishes a sound and effective carbon trading market.

\section{Chinese Carbon Emission Rights to Confirm and Measure}

Enterprises have control the resources, and is expected to bring economic benefits to the enterprise. "The resources owned or controlled by the enterprise" means that the ownership of the resource is owned by the enterprise. Or, even if the ownership can not be entirely owned by the enterprise, the enterprise should be able to control the resource. From the perspective of ownership to understand the "possession" has "possess", "possession" of the meaning; and "control" can also be understood as "disposal" and 'dominate.' Therefore, to determine whether a resource can be owned or controlled by the subject, The key is to see whether the subject has the autonomy of the resources of the right, rather than the absolute "all." August 20113 newly promulgated the "management approach" will be the original "management approach" in the "greenhouse gas Emissions of resources owned by the Chinese government "abolished, clearly shows that the government of the project development enterprises have the right to control the actual carbon emission control of the project after the successful development of the output of Lu carbon reduction of the relevant income by $2 \%$ to $65 \%$ The proportion of the amount paid to the country, retained part of the enterprise's own economic interests of the inflow. It can be seen, CDM project development enterprises on their own development is expected to bring economic benefits to the enterprise carbon emissions reduction of substantial disposal right.

Identify a resource as an asset, in addition to meeting the definition of the above assets, it should also meet: the resource-related economic benefits are likely to flow into the enterprise; CDM project after the issuance of EB to reach the scheduled sales status, and China Project owners in the application for CDM before the general cooperation with foreign partners have signed a sales contract, after the success of the successful sale, to achieve the interests of economic inflows. (2) the cost or value of the resource can be measured reliably. CDM in the formation of carbon emission reduction process, from the early identification of the project to the late registration fees, inspection fees, and then to the success of the product after the success of the market transactions in the certification fees, the relevant taxes and fees are able to reliably measured of. Moreover, in accordance with Article 15 of the Administrative Measures, CDM projects must provide a negotiable carbon price at the time of approval. Therefore, the cost of carbon emission reductions from CDM projects is able and must be able to be reliably measured. Therefore, Chinese CDM project development of carbon emission rights in line with the recognition of corporate assets, should be recognized as an asset of the enterprise.

Historical costs, also known as the original cost, the actual cost, is to obtain an asset when the actual payment of cash or other cash equivalents, representing the enterprise in the acquisition of the value of the assets. The application of historical cost in carbon emissions trading mainly refers to the initial price of carbon emission reductions. Historical costs are formed in the market, 
representing the two sides agree that the price of the transaction, the relevant transaction information is easy to obtain, and has a strong verifiability and reliability. The application of historical cost measurement in Chinese carbon emissions trading problem, mainly refers to the initial measurement of carbon emission reduction. Chinese CDM project owners in the development of carbon emission reduction process, the relevant costs can be reliably measured by the transaction certificate as the basis for the actual price as the development of carbon emission reduction of the initial cost is reasonable and reliable.

International Accounting Standards The definition of fair value is "in the fair trade, the parties familiar with the situation voluntarily according to the amount of asset exchange or debt settlement." Defined by the fair value of the fairness is emphasized, can be understood as the current fair of the market value of the transaction. On the initial trading day, transaction costs are measured at current market value, at which point the fair value and historical cost are consistent. After any date, the fair value shall be determined on the basis of the market price at that time. Compared with the historical cost, the fair value can better reflect the economic nature of carbon emissions trading. For an enterprise, the economic value of carbon emissions trading should be the proceeds from the sale and the cost of compensation for the emission of room gases, whichever is greater. If the proceeds from the sale of carbon emissions are greater, rational business managers will obviously choose to sell. Therefore, the fair value can reflect the opportunity cost of holding carbon emissions, the use of fair value measurement is more conducive to enterprises to make the right decision. However, compared with developed countries, China is still a new market economy countries, the application of fair value in China is cautious, appropriate, conditional and selective. Moreover, the carbon emissions trading are an emerging market, all aspects are not mature, is still in the exploratory stage, if not limit the use of fair value, there may be fair value "unfair" phenomenon, and even appear to manipulate profits Case. Therefore, in the initial stage of Chinese carbon emissions trading, it is not easy to use the fair value measurement model.

According to Chinese "Accounting Standards for Business Enterprises No. 6 an intangible assets" Article XIII, intangible assets should be based on the initial cost of measurement. IE the initial measurement of carbon emissions is measured at cost. In order to more accurately measure the cost of carbon emission reductions, it is necessary to understand the formation and sales process of carbon emission reductions. A CDM project from the beginning of the design, application to the implementation of the development of carbon emission reduction, and then to the final sale, the need for the following steps:

The first step is to the China Development and Reform Commission to apply for the project. The National Development and Reform Commission and the Clean Development Mechanism Project Audit Council organize experts to review CDM projects.

The second step, after the completion of the application of CDM development enterprises to designate an independent business entity, to be responsible for the CDM project design and testing programs and project design documents and other information for validation, and to the CDM Executive Board (EB) to submit the project validation report. Complete this step before you can apply for registration with EB.

The third step, the Clean Development Mechanism Executive Board (EB) decision, including project registration, project financing and monitoring the verification of carbon emission reductions, carbon emission reductions issued. Among them, the project financing is the CDM project can successfully complete the key link. Only the project successfully found the investor, then all of its preparatory work to be completely come to an end, CDM project was officially began to produce carbon emission reduction. Thereafter, the operational entity designated by the second step carries out periodic verification of the emission reductions generated by the project. According to the verification of the test data and calculation methods, can accurately calculate the project to produce carbon emission reduction. If the designated operational entity considers that the project testing data and the calculation procedure are correct, it will submit a certified report to the project Party and the EB to confirm that the project has generated a certain amount of carbon emission reductions. Within 15 days after the submission of the certification report, more than three EB members or project 
Parties have not submitted a reassessment of the issuance of certified carbon emission reductions, it is considered that the carbon emission reductions from CDM projects are automatically approved.

\section{Conclusion}

In this paper, the accounting treatment of Chinese carbon emissions trading as the theme of the study, trying to use the traditional financial accounting theory to explain the carbon emissions accounting issues. Carbon emissions trading has a new market-oriented means of resource management, with different from the general resources held by the characteristics of enterprises. However, it also has the general nature of corporate assets, and therefore laid the basis for it can use traditional financial accounting theory for accounting treatment. It is worth noting that, due to the specific operation of carbon emissions trading and measurement of the existence of the particularity, making the carbon emissions trading accounting must be on the traditional financial accounting theory necessary adjustments, changes, breakthroughs and innovation. Because of the complexity of accounting for carbon emissions trading, it is necessary to establish guidelines or systems for accounting of carbon emissions trading.

\section{References}

[1] Zhang Qiaoliang, Chen Liangshu. Carbon disclosure project information on the investigation report and analysis [J]. China Certified Public Accountant, 2011 (05)

[2] Wang Fangjun, Zhu Lixin, Huang Kan. Study on National Carbon Emission Information Disclosure System in Low Carbon Economy [J]. Journal of Science Research, 2011 (04)

[3] Shen Jinrong, Zhao Yijiang. Chinese CDM project enterprises carbon emissions accounting [J]. Finance Monthly, 2011 (08)

[4] Li Chenchen. Accounting and measurement of carbon emissions under different market maturity [J]. Finance Monthly, 2010 (36)

[5] Liu Xiaoqiu. Analysis of wind power CDM project development period cost and accounting [J]. China Management Information, 2010 (24)

[6] Ye Junqiao. Zhejiang Wind Power CDM project case analysis and research [J]. Northern Economy, 2010 (24) 